\title{
The University of Tokyo Center for Philosophy
}

\author{
SATŌ Sora*
}

The University of Tokyo Center for Philosophy 共生のための国際哲学研 究センター, from 2002 to 2012, operated as a 21st Century Center of Excellence Program and a Global Center of Excellence Program under the Ministry of Education, Culture, Sports, Science, and Technology, and then from April 2012 it received support from the Uehiro Foundation on Ethics and Education. In its Uehiro Research Division for Philosophy of Coexistence, established in April 2012, it asks how we should handle such common human problems as the increasing diversity of and conflict between values brought on by rapid globalization; how we should deal with different ethnic groups, different religions, different cultures, and different societies; and what the proper relation should be between the global environment and people and between science and people. And to deal with such issues, it promotes the idea of coexistence. The research division is also forming an interdisciplinary network of domestic and international scholars interested in philosophical practical knowledge and is training young researchers to be at the forefront in handling such problems in the near future.

The Uehiro Research Division has established three large projects as part of its core research training project: "Dialogical Practice between Eastern and Western Philosophy," "Philosophy of Disability and Co-existence," and "Philosophy for Everyone." It also has projects for training researchers in development research. These are flexible, challenging projects to support its large projects. The large projects and small projects complement one another and are also designed to evolve according to future needs. In addition, the Center for Philosophy publishes the results of some of its activities in booklet form (for details about publications, please see the website listed at the end of this article).

Below is information about the research division's large projects and its activities in the last fiscal year.

* Satō Sora 佐藤空 is a research assistant at the University of Tokyo Center for Philosophy. 


\section{Dialogical Practice between Eastern and Western Philosophy, a Practicum}

The "Dialogical Practice between Eastern and Western Philosophy" project is a practicum of international collaborative research that seeks to readdress the relationship between traditional and modern, and between the West and Japan/East Asia. Such a practicum is no doubt a much-needed scholarly endeavor in today's ever more globalized world. In our last fiscal year, we were active in building an international exchange network for philosophical research with a view toward examining the possibility of an East Asian philosophy. In addition, we also carried out the following three international scholarly exchanges in pursuing the objectives of this project.

- "A New Universality for East Asia," an international conference hosted by Yonsei University and the University of Tokyo Center for Philosophy, April 2014. This collaborative project with Paek Yŏng-sŏ 白永瑞氏 and Kim Hang 金杭 of Yonsei University sought to give new meaning to the term "universal" in the East Asian context. In the future we plan to add East China Normal University to the project in the expectation that positive interactions between scholars of various Asian countries will produce results not seen before.

- A training seminar, in English, on the history of Japanese philosophy, jointly sponsored with Kyoto University, November 2014. Students from Kyoto University and the University of Tokyo Center for Philosophy, together with a scholar of Japanese philosophy in the United States, met and read through Nishida Kitarō 西田幾多郎 in English. Needless to say, discussing Japanese philosophy in an international setting requires reading it in English. Our purpose in having young scholars participate in this exercise was to enable them to engage positively in international forums in the future.

- Workshop on Religion and Modernity in the Context of East Asian Philosophy, January 2015. At National Chengchi University in Taipei, we held a workshop on Buddhism and modern developments in East Asian philosophy. The intent of the workshop was to consider the influence of Buddhist philosophy, which played an important role in the formation of East Asian philosophy. In the future the workshop will focus on Mahayana shraddhotpada shastra (Treatise on the Awakening of Faith in the Mahayana 大乗起信論).

In this way the present project has sought clues for solutions to problems facing modern societies by engaging in international scholarly exchanges and closely collaborating with foreign scholars. 


\section{The Philosophy of Disability and Co-existence}

This second large project consisted mainly of holding the conference "Philosophy of Disability and Co-existence," but it also required building a network of involved persons and researchers of various fields both in Japan and abroad, and it produced many unique studies and practices. With Dr. Tom Shakespeare, one of Britain's leading researchers in disability studies, we planned, in September 2014 in Norwich, Britain, a workshop introducing studies of involved persons (which were put into practice in places like Bethel House in Urakawa, Hokkaido), and we presented a report. In November we cohosted a lecture by Roberto Mezzina, the director of the Department of Mental Health in Trieste who deinstitutionalized the local psychiatric hospital in favor of alternative community services. And in February 2015 we jointly hosted the symposium "Knowledge/Technology of Birth" with the Research Center for Ars Vivendi at Ritsumeikan University. Since these events were well received both in Japan and internationally, we can expect more progress on this project going forward. In the future we will strengthen the research network we have built and expand our collaboration with other organizations. We also plan to revisit such issues as what counts as a disability and why have we needed the concept of disabilities, and in this way to elaborate on the philosophy of disability as it applies to the notion of coexistence. By means of this work, we plan to explore whether the concept of disability and the theme of coexisting with disabilities are necessary in the first place.

\section{Philosophy for Everyone}

This third large project seeks, by means of dialog, to open philosophy to everyone in all sorts of settings, something that is as simple as asking, thinking, and speaking. It is also an attempt to treat collaboration as the impetus for philosophy. In particular, during the last three years, we have held philosophical dialogs in such settings as philosophy cafés, philosophy education sessions in schools, and local community-building efforts. On numerous occasions, we have seen people of different ages, generations, sexes, occupations, nationalities, cultures, and backgrounds, in dialog, raise positions and assumptions, and deepen and expand their appreciation of others. In our last fiscal year, we cooperated with people involved in the second large project, and we began collaboration with nonacademics such as theater personnel, designers, farmers, healthcare professionals, and elderly people and housewives active in local communities. As a result of our efforts, we enlarged the space for philosophical dialogue in comparison with when project began. In the future we hope to continue hosting workshops on various themes, expand our network of practitioners, experts, and educators both in Japan and abroad, 
and strengthen our cooperation with specialists and other nonacademics.

This is but a brief summary of our large projects. For those wanting more information on the University of Tokyo Center for Philosophy, please visit http://utcp.c.u-tokyo.ac.jp/. 